\title{
Numerical Model for Sediment Transport over Nonplanar, Nonhomogeneous Surfaces
}

\author{
Gokmen Tayfur ${ }^{1}$ and Vijay P. Singh, F.ASCE ${ }^{2}$
}

\begin{abstract}
Sediment transport on surfaces with spatially variable microtopography, roughness, and infiltration was investigated using the diffusion wave equation. An implicit finite-difference scheme together with multivariate Newton's method was employed to solve the equation numerically. The simulation results showed that microtopography and roughness were the dominant factors causing significant spatial variations in sediment concentration. If the spatially varying microtopography was replaced by an average constant slope, the result was an overestimation of the sediment load. On the other hand, when the spatially varying roughness was replaced by the average roughness and the spatially varying infiltration rate by the average infiltration rate, the sediment discharge was not significantly affected. The sedimentograph reached an equilibrium much sooner when a constant infiltration rate was substituted for the time-varying infiltration rate.
\end{abstract}

DOI: 10.1061/(ASCE)1084-0699(2004)9:1(35)

CE Database subject headings: Numerical models; Sediment transport; Infiltration; Sediment concentration; Wave equations.

\section{Introduction}

Surface erosion is the most fundamental cause of soil loss in forest, agricultural, and urban watersheds ( $\mathrm{Li} 1979$ ). One of the dominant driving causes of surface erosion is the rainfall-runoff process. Natural hillslopes on which erosion is generated by the rainfall-runoff process are seldom planar with homogeneous physical and hydraulic characteristics. Microtopography, surface roughness, and soil characteristics vary over short distances, and they strongly influence the dynamics of flow and sediment transport and the consequent hillslope hydrograph and sedimentograph.

Physically based mathematical models of rainfall-runoff induced surface erosion have been developed by Negev (1967), Rowlinson and Martin (1971), Smith (1976), Singh (1983), Woolhiser et al. (1990), and Tayfur (2001), among others. Most of these models are 1D and usually approximate the highly irregular microtopography of a smooth surface. This is done to avoid complications arising in the numerical solution and the extra effort involved in obtaining the microtopographic data at a grid scale required by the numerical method. Furthermore, these models assume uniform surfaces with homogeneous soil properties and consequently do not allow for varying roughness and infiltration to occur over surfaces. In addition, they employ the kinematic wave approximation, which cannot accommodate the backwater

\footnotetext{
${ }^{1}$ Associate Professor, Dept. of Civil Engineering, Faculty of Engineering, Izmir Institute of Technology, Gulbahcekoyu, Urla, Izmir 35347, Turkey. E-mail: tayfur@likya.iyte.edu.tr

${ }^{2}$ A. K. Barton Professor, Dept. of Civil and Environmental Engineering, Louisiana State Univ., Baton Rouge, LA 70803-6405. E-mail: cesing@1su.edu

Note. Discussion open until June 1, 2004. Separate discussions must be submitted for individual papers. To extend the closing date by one month, a written request must be filed with the ASCE Managing Editor. The manuscript for this paper was submitted for review and possible publication on June 4, 2002; approved on February 24, 2003. This paper is part of the Journal of Hydrologic Engineering, Vol. 9, No. 1, January 1, 2004. CASCE, ISSN 1084-0699/2004/1-35-41/\$18.00.
}

effects occurring as a result of nonuniform conditions. As a result, these models oversimplify the actual process leading to soil erosion.

Most natural surfaces have highly irregular microtopographies with nonhomogeneous soil properties. Since rainfall and runoff are the driving agents of soil erosion, the processes of detachment, transport, and deposition are much influenced by the local flow depth, velocity field, and roughness. Therefore, for realistic simulation the erosion process should be treated in two dimensions, and the actual varying microtopography, roughness, and soil properties need to be incorporated into physically based soil erosion models.

The objective of this study is to develop a physically based numerical model for simulating erosion and sediment transport over non planar surfaces with nonhomogeneous soil properties. To that end, the model would employ the diffusion wave approximation to overcome the shortcomings of the kinematic wave approximation. The erosion process consists of the dynamics of flow, erosion, and sediment transport. Zhang and Cundy (1989) and Tayfur et al. (1993) investigated the dynamics of flow under spatially varying slope, roughness, and infiltration. This study would investigate the dynamics of erosion and sediment transport under spatially varying conditions.

\section{Development of Mathematical Model}

Modeling of soil erosion induced by the rainfall-runoff process entails (1) flow dynamics and (2) erosion and sediment transport dynamics. From flow dynamics, one computes the flow depth and velocity field on the land surface and the flow discharge from the land surface. The flow depth and velocity field so computed are, in turn, used in the erosion and sediment transport dynamics to obtain the sediment concentration field on the land surface and the sediment discharge from the land surface. This approach assumes that the sediment concentrations in the overland flow regime are sufficiently small that the suspended sediment does not affect the flow dynamics. 


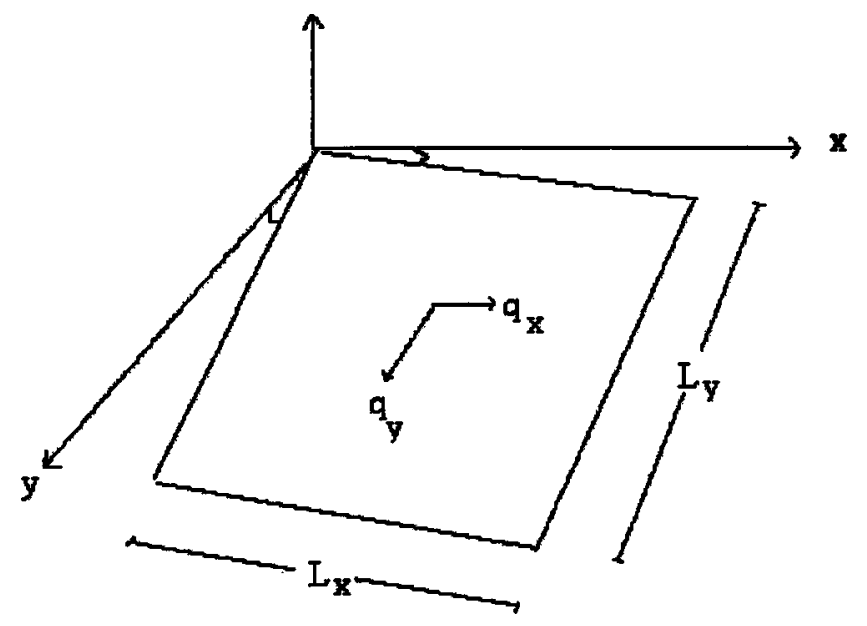

Fig. 1. Definition sketch for $2 \mathrm{D}$ overland flow

\section{Flow Dynamics}

The diffusion-wave equation in two dimensions can be expressed as (Govindaraju et al. 1992)

$$
\frac{\partial h}{\partial t}+\frac{\partial}{\partial x}\left(C_{x} h^{5 / 3}\right)+\frac{\partial}{\partial y}\left(C_{y} h^{5 / 3}\right)=(R-I)
$$

where

$$
\begin{gathered}
C_{x}=\frac{\left(S_{x}-\frac{\partial h}{\partial x}\right)^{0.5}}{n\left[1+\left(\frac{S_{y}-\frac{\partial h}{\partial y}}{S_{x}-\frac{\partial h}{\partial x}}\right)^{2}\right]^{0.25}} \\
C_{y}=\frac{\left(S_{y}-\frac{\partial h}{\partial y}\right)^{0.5}}{\left[1+\left(\frac{S_{x}-\frac{\partial h}{\partial x}}{S_{y}-\frac{\partial h}{\partial y}}\right)^{2}\right]^{0.25}}
\end{gathered}
$$

where $h=$ overland flow depth (L); $R=$ rainfall intensity $(\mathrm{L} / \mathrm{T}) ; I$ $=$ infiltration rate $(\mathrm{L} / \mathrm{T}) ; n=$ Manning's roughness coefficient $\left(\mathrm{L}^{1 / 3} / \mathrm{T}\right)$; and $S_{x}$ and $S_{y}=$ bed slopes in the $x$ - and $y$-directions, respectively, as shown in Fig. 1. Infiltration rate $(I)$ in this study was modeled by assuming a constant infiltration rate and by the Green-Ampt infiltration model (Mein and Larson 1973; Rawls et al. 1983). The Green-Ampt infiltration model described by Rawls et al. (1983) was employed in this study; note that this model assumes that the infiltration rate is independent of the overland flow depth.

Solution of Eq. (1) requires an initial condition and conditions at the upstream and downstream boundaries. The top boundary is the upstream boundary with respect to the $y$-direction and the left boundary is the upstream boundary with respect to the $x$-direction (Fig. 1). Similarly, the bottom boundary is the downstream boundary with respect to the $y$-direction and the right boundary is the downstream boundary with respect to the $x$-direction (Fig. 1). The upstream boundary conditions were expressed as the zeroflow depth and the downstream boundary conditions by the zeroflow depth gradient. The zero depth and zero-depth gradient boundary conditions have been commonly used in the literature (Morris 1979; Tayfur et al. 1993; Tayfur and Kavvas 1994; Singh 1996, 1997; Tayfur 2001, 2002). Initially, the flow starts on a dry surface.

\section{Erosion and Sediment Transport Dynamics}

Considering only the advective transport and neglecting the diffusion/dispersion mixing, the erosion and sediment transport equation in two dimensions can be expressed as (Tayfur 2001)

$$
\frac{\partial(h c)}{\partial t}+\frac{\partial}{\partial x}\left(q_{x} c\right)+\frac{\partial}{\partial y}\left(q_{y} c\right)=\frac{1}{\rho_{s}}\left[\alpha R^{\beta}+\sigma\left(T_{c}-q_{s}\right)\right]
$$

where

$$
\begin{gathered}
q_{x}=C_{x} h^{5 / 3} \\
q_{y}=C_{y} h^{5 / 3} \\
q_{s}=\rho_{s} c\left(q_{x}^{2}+q_{y}^{2}\right)^{0.5} \\
T_{c}=\eta\left[\gamma h\left(S_{x}^{2}+S_{y}^{2}\right)^{0.5}-\delta_{s}\left(\gamma_{s}-\gamma\right) d\right]^{k_{1}}
\end{gathered}
$$

where $c=$ sediment concentration by volume $\left(\mathrm{L}^{3} / \mathrm{L}^{3}\right) ; \rho_{s}$ $=$ sediment particle density $\left(\mathrm{M} / \mathrm{L}^{3}\right) ; q_{x}$ and $q_{y}=$ unit flow discharges in the $x$ - and $y$-directions, respectively $\left(\mathrm{L}^{2} / \mathrm{T}\right) ; q_{s}=$ unit sediment discharge in flow direction $(\mathrm{M} / \mathrm{L} / \mathrm{T}) ; \alpha=$ soil detachability coefficient whose range is $0.00012-0.0086 \mathrm{~kg} / \mathrm{m}^{2} / \mathrm{mm}$ (Sharma et al. 1993); $\beta=$ constant whose range is $1-2 ; \sigma$ $=$ transfer rate coefficient whose range is $3-33(\mathrm{~L} / \mathrm{m})$ (Foster 1982); $T_{c}=$ transport capacity of sheet flow in flow direction (M/ $\mathrm{L} / \mathrm{T}$ ); $\eta=$ soil erodibility coefficient whose range is $0-1.0$ (Foster 1982); $\gamma_{s}=$ specific weight of sediment $\left(\mathrm{M} / \mathrm{L}^{2} / \mathrm{T}^{2}\right) ; \gamma=$ specific weight of water $\left(\mathrm{M} / \mathrm{L}^{2} / \mathrm{T}^{2}\right) ; \delta_{s}=$ constant of 0.047 (Gessler 1965); $d=$ particle diameter (L); and $k_{1}=$ exponent whose range is 1.0-2.5 (Foster 1982).

The first term inside the brackets on the right-hand side of Eq. (4) stands for the soil detachment rate by raindrops, and the second term represents the soil detachment and deposition rate by sheet flow. Tayfur (2001) showed that the raindrop maximum penetration depth $\left(z_{m}\right)$ is much greater than the flow depth plus the loose soil depth $\left(z_{w}\right)$, that is, $z_{m} \gg z_{w}$. Hence this study assumes that $z_{m} \gg z_{w}$. As a result, the soil detachment rate by raindrops is expressed by the first term on the right-hand side of Eq. (4). In this equation, when the transport capacity exceeds the existing unit sediment discharge $\left(T_{c}>q_{s}\right)$, the flow will detach soil particles; otherwise it will deposit the particles. In Eq. (8), the first term inside the brackets on the right-hand side stands for the shear stress and the second represents the critical shear stress, which is very small for cohesionless soils and is often neglected (Foster 1982).

The upstream boundary condition was taken as the zero sediment concentration and the downstream boundary conditions as the zero sediment concentration gradient. The zero sediment concentration and zero sediment concentration gradient boundary conditions have also been used by Govindaraju and Kavvas (1991) and Tayfur $(2001,2002)$. Flow starts on a dry surface. On a tilted hillslope where the flow is mainly in two dimensions (Fig. 1), at the upstream boundaries (the top and left boundaries in Fig. 1) one would expect a zero flow depth and consequently a zero sediment concentration. Over very mild tilted hillslopes, however, one may perhaps observe a very thin flow at the lower parts of the upstream boundaries. Yet even in such cases the zero boundary condition (zero flow depth and zero sediment concentration) as- 


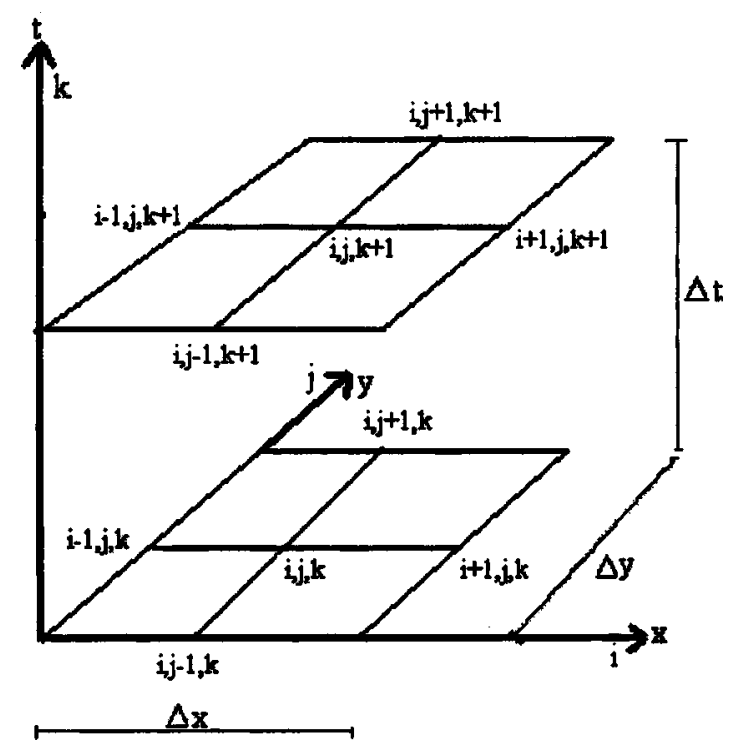

Fig. 2. Computational cell for implicit finite-difference scheme

sumption may not significantly alter the simulation results, which is the reason the zero boundary conditions have been commonly employed in the literature.

\section{Solution Procedure}

Eqs. (1) and (4) are solved by the implicit centered finitedifference method. Fig. 2 shows a typical computational cell where $i$ and $j=$ spatial node numbers in the $x$ - and $y$-directions, respectively; $k=$ time step number; $\Delta x$ and $\Delta y=$ space interval lengths in $x$ - and $y$-directions, respectively; and $\Delta t=$ time step. The finite-difference form of Eqs. (1) and (4) can be written as follows:

$$
\begin{aligned}
& F_{i, j}=\frac{h_{i, j}^{k+1}-h_{i, j}^{k}}{\Delta t}+\frac{\theta}{2 \Delta x}\left[\left(q_{x}\right)_{i+1, j}^{k+1}-\left(q_{x}\right)_{i-1, j}^{k+1}\right] \\
& +\frac{(1-\theta)}{2 \Delta x}\left[\left(q_{x}\right)_{i+1, j}^{k}-\left(q_{x}\right)_{i-1, j}^{k}\right]+\frac{\theta}{2 \Delta y}\left[\left(q_{y}\right)_{i, j+1}^{k+1}\right. \\
& \left.-\left(q_{y}\right)_{i, j-1}^{k+1}\right]+\frac{(1-\theta)}{2 \Delta y}\left[\left(q_{y}\right)_{i, j+1}^{k}-\left(q_{y}\right)_{i, j-1}^{k}\right] \\
& -\left[\theta(R-I)_{i, j}^{k+1}+(1-\theta)(R-I)_{i, j}^{k}\right]=0.0 \\
& E_{i, j}=\frac{(h c)_{i, j}^{k+1}-(h c)_{i, j}^{k}}{\Delta t}+\frac{\theta}{2 \Delta x}\left[\left(q_{x} c\right)_{i+1, j}^{k+1}-\left(q_{x} c\right)_{i-1, j}^{k+1}\right] \\
& +\frac{(1-\theta)}{2 \Delta x}\left[\left(q_{x} c\right)_{i+1, j}^{k}-\left(q_{x} c\right)_{i-1, j}^{k}\right]+\frac{\theta}{2 \Delta y}\left[\left(q_{y} c\right)_{i, j+1}^{k+1}\right. \\
& \left.-\left(q_{y} c\right)_{i, j-1}^{k+1}\right]+\frac{(1-\theta)}{2 \Delta y}\left[\left(q_{y} c\right)_{i, j+1}^{k}-\left(q_{y} c\right)_{i, j-1}^{k}\right] \\
& -\left(\left\{\frac{\theta}{\rho_{s}}\left[\alpha R^{\beta}+\sigma\left(T_{c}-q_{s}\right)\right]\right\}_{i, j}^{k+1}\right. \\
& \left.+\left\{\frac{(1-\theta)}{\rho_{s}}\left[\alpha R^{\beta}+\sigma\left(T_{c}-q_{s}\right)\right]\right\}_{i, j}^{k}\right)=0.0
\end{aligned}
$$

where $F_{i, j}$ and $E_{i, j}$ are the finite-difference approximations of Eqs. (1) and (4) at node $(i, j)$, respectively, as shown in Fig. 2, and $\theta$ is the weighting parameter, which was taken as 0.75 .

The multivariate Newton-Raphson iterative technique was used to solve the set of nonlinear equations resulting from the implicit procedure. The details of the numerical scheme are given in Tayfur (1990). Under the specified initial and boundary conditions, Eqs. (1) and (4) were solved simultaneously for each time step. Eq. (1) was first solved to obtain flow depths on the surface and unit discharges from the surface, which were then used in Eq. (4) to compute sediment concentrations on the surface and unit sediment discharge from the surface.

\section{Simulation and Analysis of Results}

The model was applied to quantitatively investigate the effect of replacing the spatially varying microtopographic surface, roughness, and infiltration rate with their corresponding average values on the erosion and sediment transport dynamics. To that end, the spatially varying microtopographic surface of an actual experimental plot was employed. For cases of a spatially varying roughness and infiltration rate, hypothetical data were generated.

The values of parameters used in the model simulations were within the ranges suggested in the literature and are as follows: Manning's roughness coefficient $(n)=0.012$; soil detachability coefficient $(\alpha)=0.0022 \mathrm{~kg} / \mathrm{m}^{2} / \mathrm{mm}$; exponent $\beta=1.80$; transfer rate coefficient $(\sigma)=24.0 \mathrm{~m}^{-1}$; exponent $k_{1}=1.5$; and soil erodibility coefficient $(\eta)=0.12$.

In the model simulation, unless specified otherwise, a 4.5 by $22 \mathrm{~m}$ plot was subjected to a $117 \mathrm{~mm} / \mathrm{h}$ rainfall intensity for a duration of $20 \mathrm{~min}$, and a $7 \mathrm{~mm} / \mathrm{h}$ constant infiltration rate and a ponding time of 2 min were also employed. Furthermore, for the Green-Ampt model, the hydraulic conductivity, wetting capillary pressure head, and porosity were assumed, respectively, as 0.65 $\mathrm{cm} / \mathrm{h}, 18 \mathrm{~cm}$, and 0.42 values. The particle diameter was assumed to be $1 \mathrm{~mm}$, and the soil was assumed to have a bulk density of $1,500 \mathrm{~kg} / \mathrm{m}^{3}$.

Tayfur et al. (1993) calibrated the flow part of the model with the experimentally observed flow discharge data of Barfield et al. (1983). Using experimentally observed sediment discharge data of Kilinc and Richardson (1973), Tayfur (2002) calibrated a 1D sediment dynamics version of the model in conjunction with the kinematic wave approximation. Since Tayfur et al. (1993) and Zhang and Cundy (1989) investigated the flow dynamics under varying microtopography, roughness, and infiltration, this study would be confined to the sediment dynamics under spatially varying conditions.

To investigate the effect of replacing a varying microtopography with a smooth surface for erosion and sediment transport, the actual varying microtopographic data for a hillslope $22 \mathrm{~m}$ long and $4.5 \mathrm{~m}$ wide, labeled S3R2A, were used (Barfield et al. 1983). A $3 \mathrm{D}$ picture of this experimental plot is given in Fig. 3. While simulating the flow variables over this hillslope with the solution of the St. Venant equations, Tayfur et al. (1993) had to smooth the soil surface to obtain a more gradually varying soil profile. Similarly, a more gradually varying soil profile was needed for the sediment transport simulation by the diffusion wave approximation used in this study. This is because when we used a very fine grid mesh width of less than $0.6 \mathrm{~m}$ in the $x$ - and $y$-directions, we found that there were very steep local slopes of about $15 \%$ and that many nodal locations, due to the depressions and crests in the soil surface, had steep negative slopes as well. These depressions 


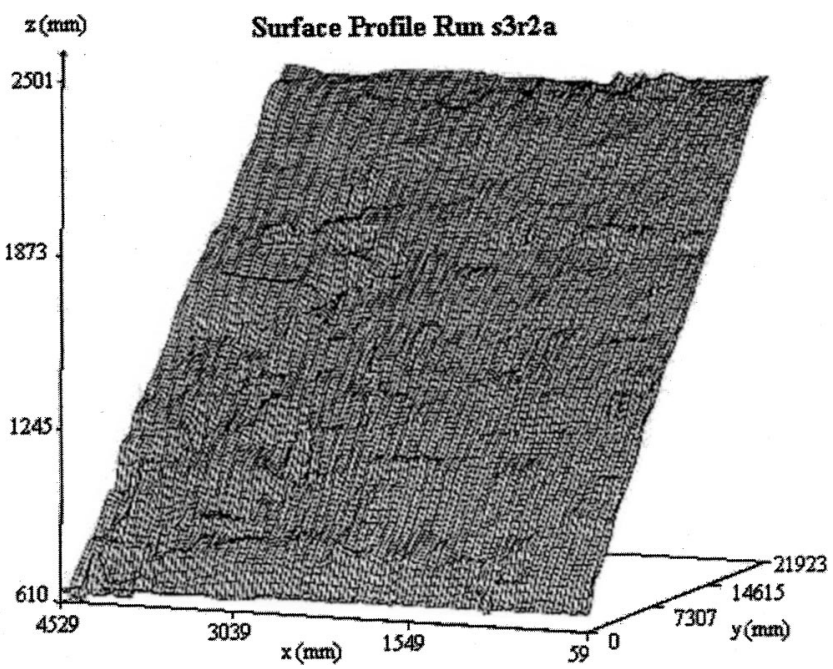

Fig. 3. Microtopographic surface profile of plot S3R2A (used with permission from Barfield et al. 1983)

lead to storage and can trigger backwater effects. The kinematic wave approximation is not designed to handle such physical situations. The numerical solution of the diffusion wave approximation also failed to converge, even with very small time steps.

The flow field in such highly variable microtopography is not like a sheet flow as perceived by the flow equations. To obtain more stable results, we considered smoothing the soil surface to obtain a more gradually varying soil profile. In the $y$-direction, the hillslope had an average slope of 0.086 and the local slopes were mostly positive and steep; hence it was sufficient to average the slope over $0.6 \mathrm{~m}$ distances in the $y$-direction. On the other hand, in the $x$ - direction, the hillslope has a milder average slope of 0.0086, but with abrupt changes in local slopes. As such, the variation in the flow was no longer gradual as perceived by the flow equations, and hence the averaging distance had to be over $1.2 \mathrm{~m}$ to get consistent numerical results. After the soil surface was averaged over 1.2 by $0.6 \mathrm{~m}$ intervals in the $x$ - and $y$-directions, respectively, local slopes in the $x$-direction $\left(S_{x}\right)$ had a range of 0.3 to $2.9 \%$, and the local slopes in the $y$-direction $\left(S_{y}\right)$ had a range of 5.6 to $10.8 \%$. Once the soil surface was smoothed in this manner, solutions were obtained by the numerical model with a nodal spacing of $0.3 \mathrm{~m}$ in each direction.

Figs. 4( $a$ and $b)$ show sediment concentration profiles over the S3R2A surface with constant average slopes $(0.86 \%$ in the $x$-direction and $8.6 \%$ in the $y$-direction) and varying microtopography, respectively, at a time equal to $20 \mathrm{~min}$. As seen in Fig. 4(a), in the case of constant average slopes the sediment concentration profile on the soil surface was smooth and gradually increased with increasing distance in the spatial directions. On the other hand, as seen in Fig. 4(b), the concentration profile was not smooth in the case of spatially varying slopes (averaged over 1.2 by $0.6 \mathrm{~m}$ intervals in the $x$ - and $y$-directions, respectively). This clearly reflects the effect of changing local slopes on the sediment concentration. Fig. 5 shows sedimentographs computed for the cases considered in Figs. 4(a and b). As is seen, the employment of average constant slopes for slope S3R2A overestimated the sediment load by about $10 \%$. In the case of varying slopes, more deposition might be occurring on the soil surface [Fig. 4(b)], and this might be resulting in less sediment yield from the plot (Fig. 5).

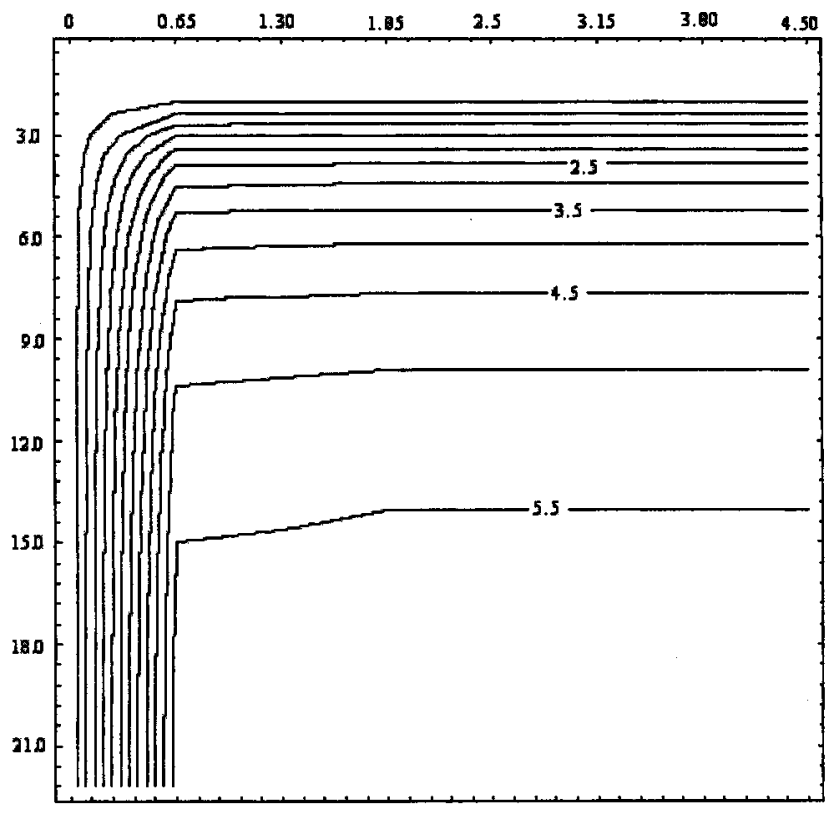

(a)

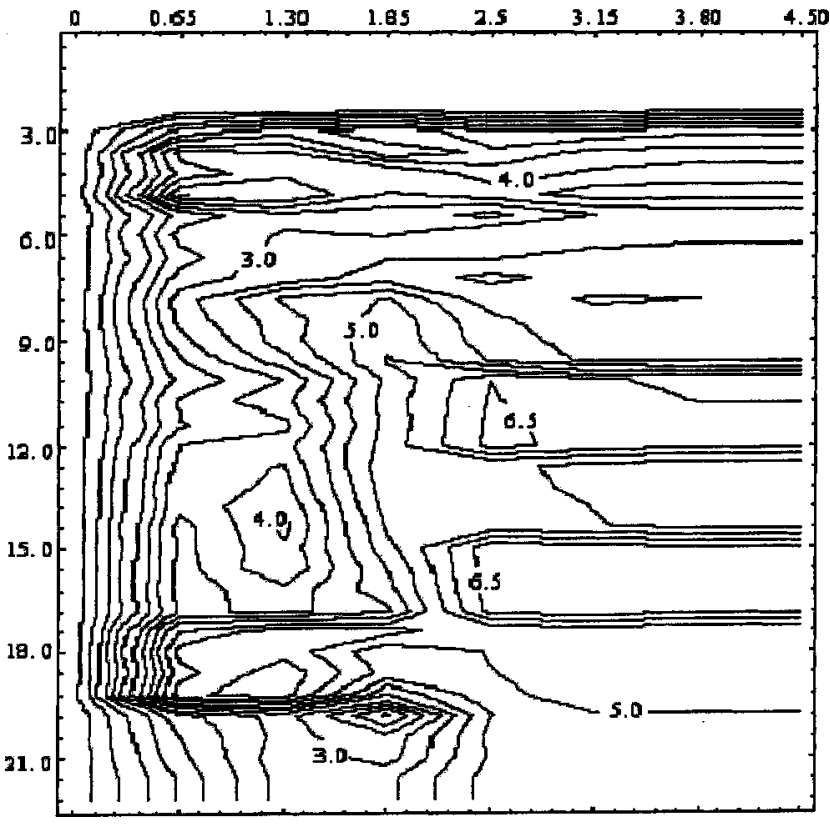

(b)

Fig. 4. Sediment concentration $(\mathrm{ppm} / 1,000.0)$ profile at simulation time of 20th minute: (a) surface has constant average slopes; (b) surface has variable slopes.

To simulate the sediment concentration profile under spatially varying surface roughness, hypothetical spatially varying surface roughness, as shown in Fig. 6, was generated according to the normal distribution function with a mean of 0.0187 and a standard deviation of 0.0066 . However, we had to make sure that the data employed were physically sound and within an agreement suggested in the literature. The range of the generated data was 0.008-0.034, which, according to Woolhiser (1974), corresponds to bare sand $(n=0.010$ to 0.016$)$, gravel surface $(n=0.012$ to 0.030$)$, and bare clay-loam soil $(n=0.012$ to 0.033$)$. Note that one may generate many different random fields of surface roughness with the same mean and standard deviation. 


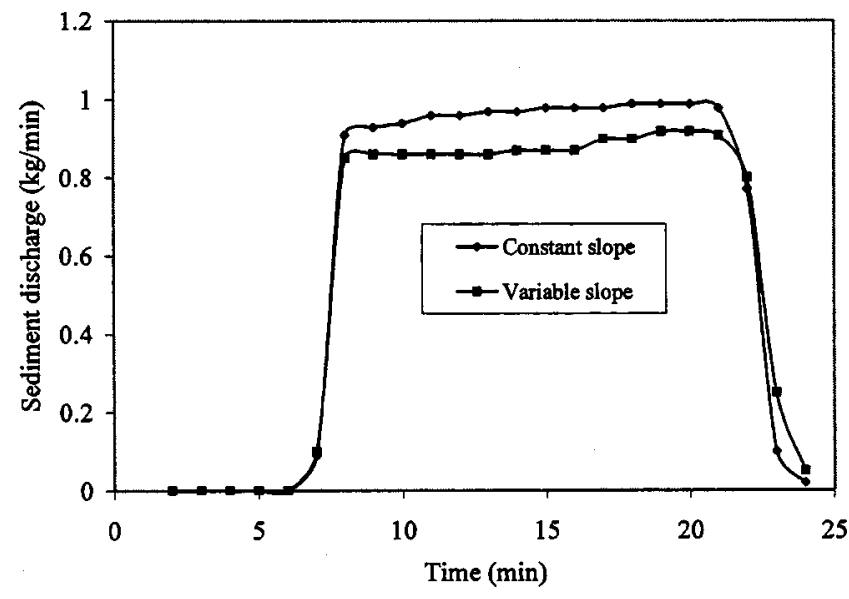

Fig. 5. Comparison of sedimentographs under constant and variable slopes

However, to have an insight into the effects of employing varying roughness, as opposed to constant average roughness, on the sediment concentration profile, one may employ only one realization, as is done in this study. The concentration, as seen in Fig. 7, had a nonsmooth profile, clearly reflecting the impact of the spatial variation of surface roughness. On the other hand, under constant roughness the sediment concentration profile on the soil surface was smooth and gradually increased with increasing distance in the spatial directions [Fig. 4(a)]

In the case of spatially varying roughness, depending on the magnitude, the soil surface deposition might be dominant in some sections and transportation be dominant in others, resulting in a nonuniform concentration profile over the surface, as shown by Fig. 7. The higher the roughness, the lower the sediment concen-

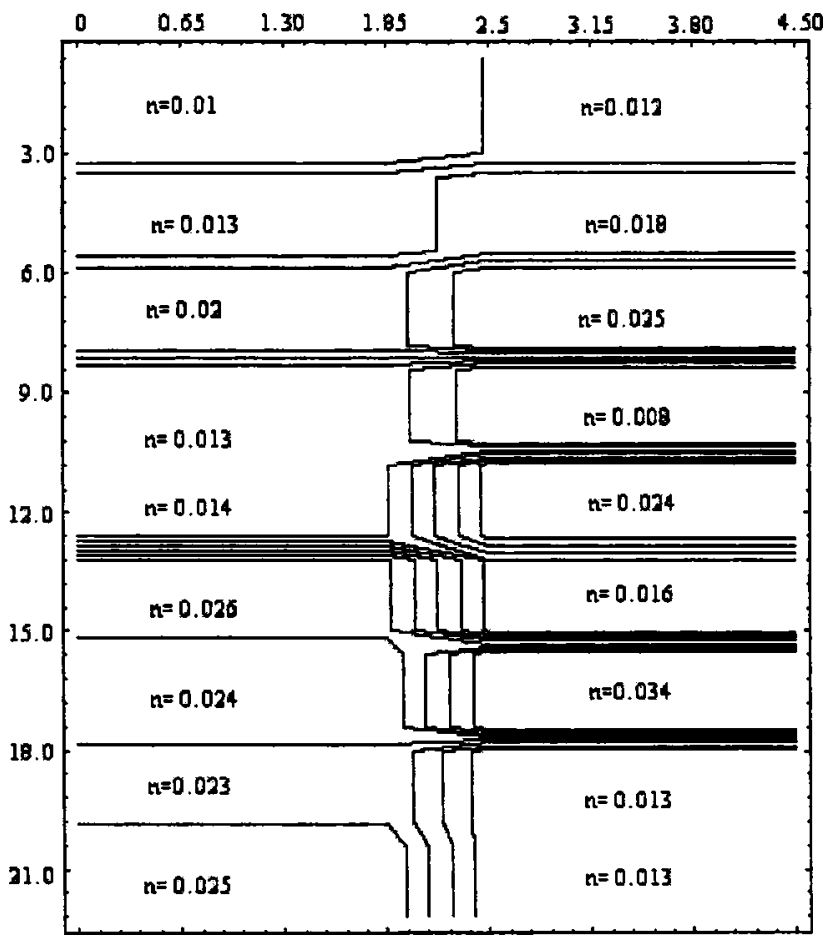

Fig. 6. Spatial distribution of surface roughness generated according to normal distribution function

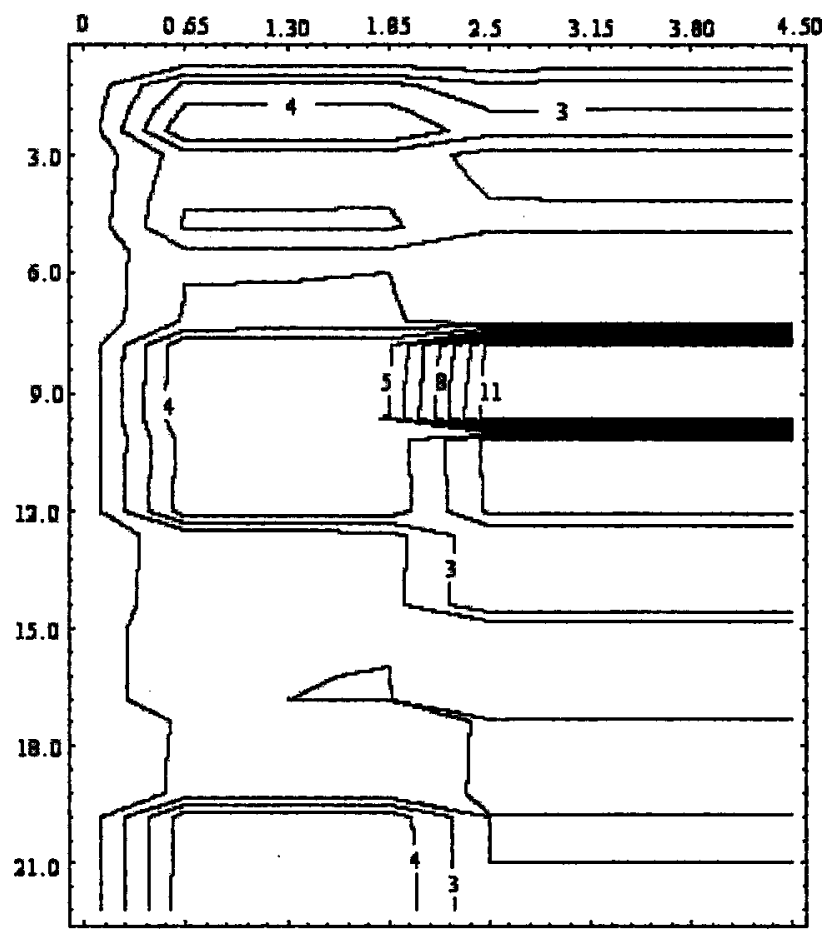

Fig. 7. Sediment concentration $(\mathrm{ppm} / 1,000.0)$ profile at simulation time of 20th minute (surface has spatially varying roughness)

tration estimated by the model (Figs. 6 and 7). A comparison of sedimentographs from both the variable and the uniform roughness surfaces $(n=0.0187)$ is shown in Fig. 8 . The results indicate that the sedimentograph computed on the basis of the uniform roughness surface well approximates that obtained from the spatially variable roughness surface.

Fig. 9 shows the sediment concentration profile under the spatially varying infiltration rate. To that end, the hypothetical spatially varying infiltration rate, as shown in Fig. 10, was generated according to the normal distribution function with a mean of $13.89 \mathrm{~mm} / \mathrm{h}$ and a standard deviation of $6.95 \mathrm{~mm} / \mathrm{h}$. However, we had to make sure that the data employed were physically sound and within an agreement suggested in the literature. The range of the generated data was 3 to $32 \mathrm{~mm} / \mathrm{h}$, which, according to Rawls

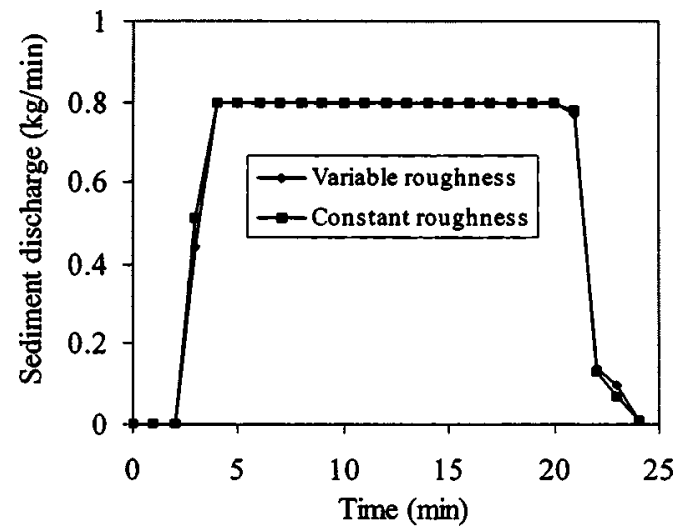

Fig. 8. Comparison of sedimentographs under constant ( $n$ $=0.0187)$ and variable roughness $($ mean $=0.0187$ and standard deviation $=0.0066$ ) 


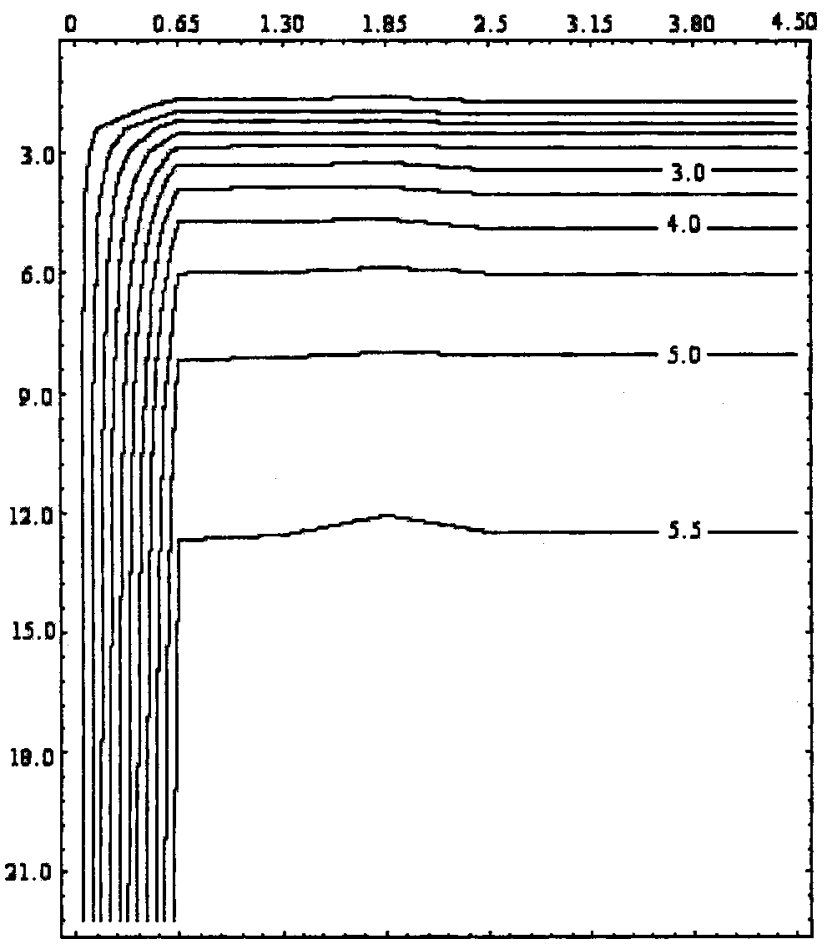

Fig. 9. Sediment concentration $(\mathrm{ppm} / 1,000.0)$ profile at simulation time of 20th minute (surface has spatially varying infiltration rate)

et al. (1983), corresponds to loam $(I=3.4 \mathrm{~mm} / \mathrm{h})$, silt loam ( $I$ $=6.5 \mathrm{~mm} / \mathrm{h})$, sandy loam $(I=11 \mathrm{~mm} / \mathrm{h})$, and loamy sand $(I$ $=30 \mathrm{~mm} / \mathrm{h})$.

Note that one may generate many different random infiltration rate fields with the same mean and standard deviation, but to have an insight into the effects of a varying as opposed to a constant

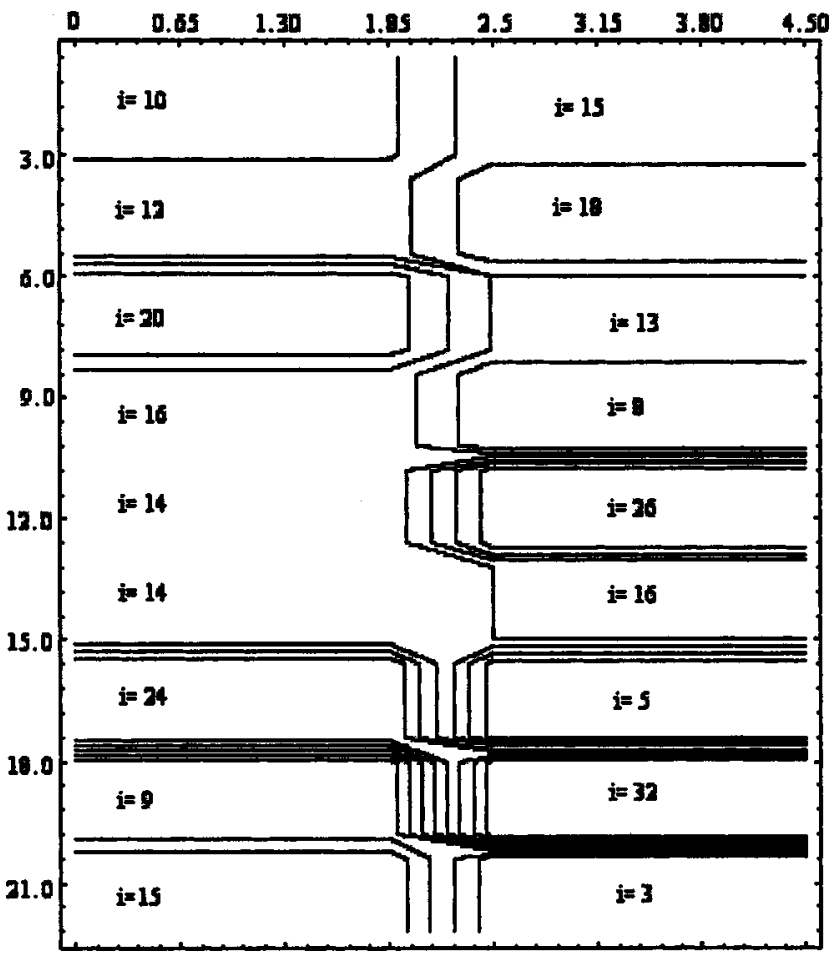

Fig. 10. Spatial distribution of steady infiltration rate generated according to normal distribution function

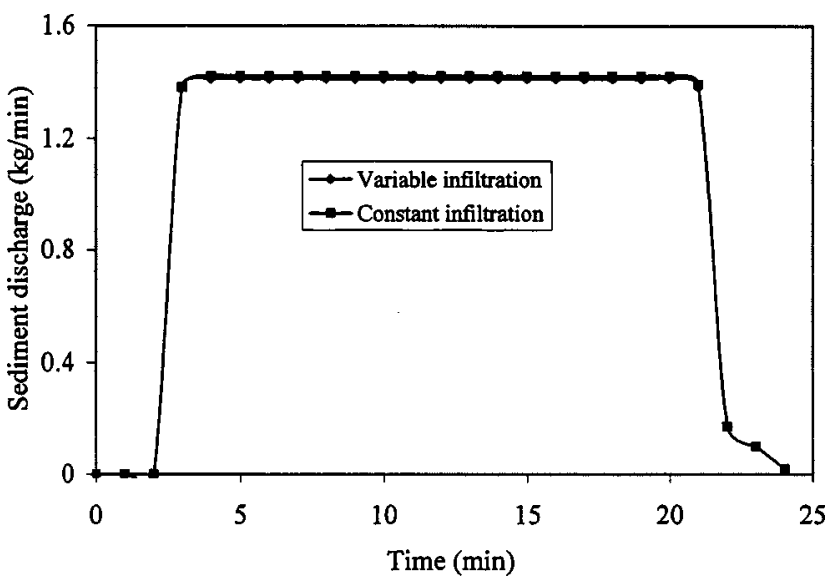

Fig. 11. Comparison of sedimentographs under constant ( $I$ $=13.89 \mathrm{~mm} / \mathrm{h}$ ) and variable infiltration rate

average infiltration rate on sediment concentration, one may employ only one realization, as is done in this study. Fig. 9 shows a concentration profile similar to that from a surface at a constant infiltration rate [Fig. 4(a)]. Fig. 11 shows sedimentographs corresponding to a spatially varying infiltration rate surface as well as the average constant infiltration rate surface $(I=13.89 \mathrm{~mm} / \mathrm{h})$. Note that hardly any difference is seen in the sedimentographs corresponding to the two cases.

Fig. 12 shows the sedimentographs simulated with the GreenAmpt infiltration model and the constant infiltration rate model using plot S3R2A, for which Tayfur et al. (1993) calibrated the Green-Ampt model parameters given above. The concentration profiles over the surface, under the two different infiltration models, had the same smooth profiles, although with different magnitudes. However, as seen in Fig. 12, the sedimentographs showed slightly different behavior. For the case shown in Fig. 12, the range of values of the Green-Ampt infiltration rates varied from 26.26 to $72.90 \mathrm{~mm} / \mathrm{h}$, with an average value of $38.03 \mathrm{~mm} / \mathrm{h}$. Hence, for the same case, we employed a $38.03 \mathrm{~mm} / \mathrm{h}$ infiltration rate for the constant infiltration rate model. As seen in Fig. 12, both models showed no difference in capturing the maximum sediment load. However, in the case of the Green-Ampt infiltration model, there was a delay of about 4 min in reaching an equilibrium load. In addition, until the end of rainfall, there was a gradual increase in the loads for the Green-Ampt infiltration model, and the recession part of the sedimentograph was slightly steeper.

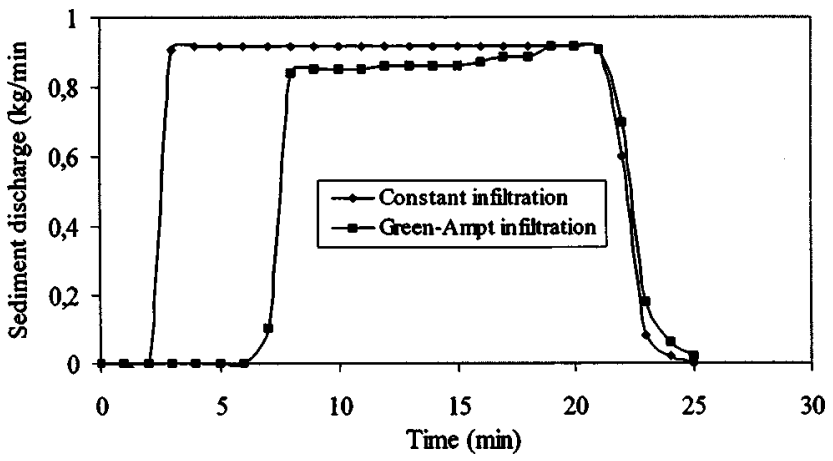

Fig. 12. Comparison of sedimentographs under constant infiltration and Green-Ampt infiltration models 


\section{Conclusions}

A 2D sediment transport model was developed for hillslopes with spatially varying microtopography, roughness, and infiltration. The following conclusions are drawn from the model results:

1. The sediment load is overestimated by about $10 \%$ if an actual spatially varying microtopography is represented by constant average slopes. Surfaces are rarely smooth by nature, and the constant-slope assumption is far from realistic.

2. When average constant infiltration was used in place of timevarying infiltration (as computed by, say, the Green-Ampt infiltration model), the sedimentograph reached an equilibrium much sooner. Time-varying infiltration is more realistic than constant infiltration, since rainfall generally starts on dry, unsaturated soil.

3. The effect of varying roughness on total sediment discharge is relatively negligible, and therefore use of constant average roughness to represent varying roughness is justified. However, as far as local erosion mitigation measures are concerned, varying roughness might be taken into account.

4. The model simulation results indicate that spatially varying infiltration can be represented by spatially averaged infiltration without undue loss of accuracy.

\section{Notation}

The following symbols are used in this paper:

$c=$ sediment concentration $\left[\mathrm{L}^{3} / \mathrm{L}^{3}\right]$;

$d=$ particle diameter $[\mathrm{L}]$

$h=$ overland flow depth [L];

$I=$ infiltration rate $[\mathrm{L} / \mathrm{T}]$;

$k_{1}=$ exponent;

$n=$ Manning's roughness coefficient;

$q_{s}=$ unit sediment discharge in flow direction $[\mathrm{M} / \mathrm{L} / \mathrm{T}]$;

$q_{x}=$ unit flow discharge in $x$-direction $\left[\mathrm{L}^{2} / \mathrm{T}\right]$;

$q_{y}=$ unit flow discharge in $y$-direction $\left[\mathrm{L}^{2} / \mathrm{T}\right]$;

$R=$ rainfall intensity $[\mathrm{L} / \mathrm{T}]$;

$S_{x}=$ bed slope in $x$-direction;

$S_{y}=$ bed slope in $y$-direction;

$T_{c}=$ transport capacity of sheet flow in flow direction $[\mathrm{M} / \mathrm{L} / \mathrm{T}]$

$\alpha=$ soil detachability coefficient $\left[\mathrm{M} / \mathrm{L}^{2} / \mathrm{L}\right]$;

$\beta=$ exponent;

$\gamma=$ specific weight of water $\left[\mathrm{M} / \mathrm{L}^{3}\right]$;

$\gamma_{s}=$ specific weight of sediment $\left[\mathrm{M} / \mathrm{L}^{3}\right]$;

$\delta_{s}=$ constant;

$\eta=$ coefficient that represents erodibility of soil;

$\rho_{s}=$ mass density of sediment particles $\left[\mathrm{M} / \mathrm{L}^{3}\right]$; and

$\sigma=$ transfer rate coefficient.

\section{References}

Barfield, B. J., Barnhisel, R. I., Powell, J. L., Hirschi, M. C., and Moore, I. D. (1983). "Erodibilities and eroded size distribution of Western Kentucky mine spoil and reconstructed topsoil." Final Rep., Institute for Mining and Minerals Research, Univ. of Kentucky, Lexington, Ky.

Foster, G. R. (1982). "Modeling the erosion process." Hydrologic modeling of small watersheds, C. T. Haan, H. P. Johnson, and D. L.
Brakensiek, eds., American Society of Agricultural Engineers, St. Joseph, Mich., 295-380.

Gessler, J. (1965). The beginning of bedload movement of mixtures investigated as natural armoring in channels, E. A. Prych, translator, W. M. Keck Laboratory of Hydraulics and Water Resources, California Institute of Technology, Pasadena, Calif.

Govindaraju, R. S., and Kavvas, M. L. (1991). "Modeling the erosion process over steep slopes: Approximate analytical solutions." J. Hydrol., 127, 279-305.

Govindaraju, R. S., Kavvas, M. L., and Tayfur, G. (1992). “A simplified model for two dimensional overland flows." Adv. Water Resour., 15, $133-141$

Kilinc, M., and Richardson, E. V. (1973). "Mechanics of soil erosion from overland flow generated by simulated rainfall." Hydrology $\mathrm{Pa}$ pers, Paper 63, Colorado State Univ., Fort Collins, Colo.

Li, R. M. (1979). "Water and sediment routing from watersheds." Modeling of rivers, H. W. Shen, ed., Wiley, New York, 9.1-9.88.

Mein, R. G., and Larson, C. L. (1973). "Modeling infiltration during a steady rain." Water Resour. Res., 9(2), 384-394.

Morris, E. M. (1979). "The effect of small-slope approximation and lower boundary conditions on solutions of the St. Venant equations." J. Hydrol., 40, 31-47.

Negev, N. (1967). "A sediment model on a digital computer." Tech. Rep. No. 76, Stanford Univ., Stanford, Calif.

Rawls, W. J., Brakensiek, D. L., and Miller, N. (1983). "Green-Ampt infiltration parameters from soils data." J. Hydraul. Eng., 109(1), 62 70 .

Rowlinson, D. L., and Martin, G. L. (1971). "Rational model describing slope erosion." J. of Irrig. and Drainage Div., 97(1), 39-50.

Sharma, P. P., Gupta, S. C., and Foster, G. R. (1993). "Predicting soil detachment by raindrops." Soil Sci. Soc. Am. J., 57, 674-680.

Singh, V. P. (1983). "Analytical solutions of kinematic equations for erosion on a plane. 2: Rainfall of finite duration." Adv. Water Resour. $6,88-95$

Singh, V. P. (1996). Kinematic wave modeling in water resources: Surface water hydrology, Wiley, New York.

Singh, V. P. (1997). Kinematic wave modeling in water resources: Environmental hydrology, Wiley, New York.

Smith, R. E. (1976). "Simulation erosion dynamics with a deterministic distributed watershed model." Proc., 3rd Federal Interagency Sedimentation Conf., Vol. 1., Water Resources Council, Washington, D.C., $163-173$

Tayfur, G. (1990). "Modeling of two dimensional overland flows." MS thesis, Univ. of California, Davis, Calif.

Tayfur, G. (2001). "Modeling two-dimensional erosion process over infiltrating surfaces." J. Hydrologic Eng., 6(3), 259-262.

Tayfur, G. (2002). "Applicability of sediment transport capacity models for nonsteady state erosion from steep slopes." J. Hydrologic Eng., $7(3), 252-259$.

Tayfur, G., and Kavvas, M. L. (1994). "Spatially averaged conservation equations for interacting rill-interrill area overland flows." J. Hydraul. Eng., 120(12), 1426-1448.

Tayfur, G., Kavvas, M. L., Govindaraju, R. S., and Storm, D. E. (1993). "Applicability of St. Venant equations for two-dimensional overland flows over rough infiltrating surfaces." J. Hydraul. Eng., 119(1), 5163.

Woolhiser, D. A. (1974). "Unsteady free-surface flow problems." Proc., Inst. on Unsteady Flow in Open Channels, Colorado State Univ., Fort Collins, Colo., 195-213.

Woolhiser, D. A., Smith, R. E., and Goodrich, D. C. (1990). "KINEROS, a kinematic runoff and erosion model: Documentation and user manual." ASR-77, Agricultural Research Service, U.S. Dept. of Agriculture, Washington, D.C.

Zhang, W., and Cundy, T. W. (1989). "Modeling of two-dimensional overland flow." Water Resour. Res., 25(9), 2019-2035. 